\title{
A TECNOLOGIA COMO SUPLEMENTO CURRICULAR: NOVAS POSSIBILIDADES PARA ALÉM DA FERRAMENTA EM SI
}

\author{
CARVALHO, Ana Paula Pereira Marques de ${ }^{1}$
}

\begin{abstract}
RESUMO
O presente texto visa destacar as potencialidades da articulação entre currículo e tecnologia, de modo a instigar, nos profissionais de educação, reflexões acerca das possibilidades de um trabaIho em sala de aula que extrapolem a utilização dos aparatos tecnológicos apenas como mais uma ferramenta. Assim, propomos a análise dessa articulação baseada no conceito de suplemento de Jacques Derrida, pois, sob o prisma da suplementaridade, significamos esse entrelace como uma produção de camadas de sentidos que se deslocam continuamente, acrescentando e modificando o conhecimento de um modo geral. Esse viés de análise nos permite inferir que a tecnologia é partícipe de um processo curricular compreendido como enunciação cultural. Assim, através das ambivalências, com base em Homi Bhabha, entendemos que os sentidos se hibridizam e simultaneamente se irrompem em múltiplas possibilidades, produzindo novas camadas de sentidos no movimento de significação entre currículo e tecnologia.
\end{abstract}

Palavras-Chave: Currículo - Tecnologia - Suplemento - Hibridismo - Produção de Sentidos.

\begin{abstract}
This paper aims at highlighting the potential of the relationship between curriculum and technology in order to foster professional educators' reflections about the possibilities of a work in the classroom that go beyond the use of technological devices as just another tool. Thus, we propose the analysis based on the supplement concept of Jacques Derrida. Therefore, from the perspective of supplementarity, we can discuss the production of layers in a continuum moving, adding up and modifying knowledge in general. This analysis allows us to infer that the technology is a participant in a curriculum process as a cultural enunciation. So, through the ambivalences, based on Homi Bhabha, we understand that the senses are hybridized and simultaneously burst into multiple possibilities, producing new layers of meaning in movement between curriculum and technology.
\end{abstract}

KeYwORDS: Technical and Curriculum Articulation - Supplement - Hybridism - Meaning Production.

\footnotetext{
${ }^{1}$ Mestranda do PROPED - Programa de Pós-Graduação em Educação da UERJ. E-mail: app_marques@yahoo.com.br
} 
Nossa história de um trabalho midiático em sala de aula ainda é lenta. Há algumas iniciativas, mas estamos presos à mera conceituação de um trabalho em sala de aula voltado para a utilização dos aparatos tecnológicos como ferramenta educacional. O Ministério da Educação tem projetado diversas ações com o propósito de apoiar os sistemas públicos de ensino na busca por soluções que promovam a qualidade na educação através da utilização da tecnologia como ferramenta educacional. No âmbito do Plano de Desenvolvimento da Educação PDE - o Guia de Tecnologias Educacionais avalia e identifica tecnologias educacionais que apresentem condições de promover a qualidade da educação básica na escola pública (BRASIL, 2014). Dessa forma, a atual gestão do Governo Federal objetiva:

\begin{abstract}
Auxiliar os gestores a conhecer e a identificar tecnologias educacionais articuladas e alinhadas com a perspectiva pedagógica da rede de ensino e da escola de modo que possam contribuir para a melhoria da educação; disseminar tecnologias educacionais em escolas e sistemas de ensino a fim de alterar o quadro educacional apresentado por boa parte dos municípios brasileiros; orientar a organização do trabalho dos profissionais da educação básica; estimular a criação de tecnologias educacionais por pessoas físicas (pesquisadores, professores etc), instituições de ensino e pesquisa, organizações sociais e demais pessoas jurídicas; fortalecer a produção teórica voltada à qualidade da educação básica, que se concretize por meio de novas tecnologias educacionais (BRASIL, 2014).
\end{abstract}

A ênfase à utilização da ferramenta tecnológica começou a se delinear como meta das políticas públicas na segunda metade dos anos 90. Segundo Barreto (2002), a utilização dos aparatos tecnológicos como ferramenta, considerados salvíficos para os problemas educacionais, foi bastante estimulada quando o Banco Mundial e a Unesco formularam políticas de empréstimos condicionados à criação de políticas educacionais voltadas para o uso intensivo da tecnologia nas salas de aula, visando exclusivamente ao aprimoramento dos professores no uso desses aparatos. Contudo, uma questão nos chama atenção e acreditamos que seja um caminho para se pensar em outras possibilidades na relação entre a educação e tecnologia, detidamente currículo e tecnologia. Nessa mesma época - anos 90 - surgiram preocupações relativas às mensagens veiculadas pela mídia, notadamente no meio televisivo. Esse novo enfoque ocasionou uma aproximação entre os setores da educação e da comunicação, ambos os campos constituindo suas ações de maneira integrada com um novo olhar sobre a influência das mídias no âmbito da escola (BARRETO, 2002).

Assim, emergiu em nosso cenário, ainda que a passos lentos, o campo MídiaEducação, contribuindo para alavancar discussões em torno de um trabalho educacional que atentasse para as mensagens veiculadas em todos os aparatos midiáticos. Inicialmente concebido em língua inglesa, o termo Media Education nasceu em paralelo à indústria cultural, nas primeiras décadas do século XX, com uma concepção chamada inoculatória, que objetivava o combate à anti-cultura dos filmes hollywoodianos. Outras concepções foram agregadas ao campo de estudo, como a concepção de leitura crítica com o objetivo de suscitar críticas a determinadas mídias; a concepção ideológica que surge em meio à ditadura militar, trazendo o produtor das mídias para o centro da cena e a concepção das ciências sociais que enfatiza a crítica aos meios de comunicação por serem importantes fontes de informação (FANTIN, 2006). 


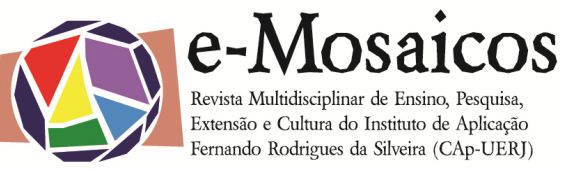

A questão principal do campo MídiaEducação é o tripé educar "pela", "com" e "para" as mídias. O educar "pela" mídia seria o uso da ferramenta em si, tendo como exemplos a tele-aula e a educação online. 0 educar "com" a mídia diz respeito à criação de um blog, um site, um livro, a produção de um filme, de um jornal. Isso viabilizaria o contato do aluno com a ferramenta para ampliar seus conhecimentos. Por fim, o educar "para" seria a postura do indivíduo diante da mídia, avaliando-a de maneira crítica, ética e esteticamente (FANTIN, 2006).

Esse tripé vem sendo trabalhado por pesquisadores renomados na área de MídiaEducação. Segundo eles, o tripé é o alicerce para a incessante análise do modo pelo qual nós interpretamos o mundo e como os outros interpretam o mundo por nós (FANTIN, 2006). Bahktin (2011) menciona a necessidade do diálogo entre sujeitos e a comunicação verbal de qualquer tipo que seja. Ele cita o livro que, sendo considerado um ato de fala impresso, além de representar um objeto de discussão ativa, precisa ser estudado a fundo, comentado e criticado.

Consideramos extremamente importante as iniciativas do Governo Federal estimulando a elaboração de projetos que visem o uso da tecnologia em sala de aula. Porém, entendemos a necessidade do "além", para algo que não se encerre na ferramenta propriamente dita. Começamos a vislumbrar possibilidades através do campo Mídia-Educação. Esse campo agrega as necessidades de uma análise crítica às mensagens veiculadas e da produção midiática, por parte dos alunos e professores, para que eles possam refletir sobre os "bastidores" das mensagens transmitidas ao leitor/telespectador. Já é um primeiro passo em direção a um outro viés sobre um trabaIho articulado entre currículo e tecnologia.
Neste sentido, entendemos que esse "além" requer enfoques teóricos que possam esgarçar a fluidez do mundo contemporâneo em que a escola está absolutamente inserida, participando desse dinamismo intensamente. Na Era da cibercultura, internet, email, facebook, twitter e outras infinitas redes sociais, estamos aqui e ali, transitando por entre fronteiras desnudas que fazem parte das nossas salas de aula. Essa é uma realidade que vem se apresentando em nossas escolas e merecem uma reflexão sobre as múltiplas facetas do espaço escolar, do currículo e dos múltiplos dizeres dos alunos, nativos digitais, no mundo da tecnologia.

Schmidt (2011) observa que o cenário mundial é hoje uma aldeia sem fronteiras, tecido pela força do capital corporativo multinacional e pela disseminação de uma cultura tecnológica de mercado. Porém, segundo a autora, vivenciamos novas formas de colonialismo que, subrepticiamente, sob a pecha de um pluralismo indiferenciado/indiferente, operam um processo intenso de neocolonização que escamoteia tensões e conflitos na simulação das equivalências. $O$ igualitarimo, a democracia, a liberdade, o acesso irrestrito às informações têm sido amplamente apregoados pelo pensamento liberal na sociedade contemporânea, como se vivêssemos num tempo linear homogêneo, estruturado por polarizações entre global e local, centro e periferia, cidadão e estranho (SCHMIDT, 2011). Esta é uma reflexão importante que corrobora com a importância de investigações que primem por uma concepção da atualidade que se desprenda da visão cultural universalista calcada em padrões imutáveis.

Assim, nesse turbilhão de informações que transitam freneticamente pelo espaço escolar, reconhecemos, primeiramente, a importância de uma discussão em torno da 
concepção de currículo. Corroboramos com Lopes e Macedo (2011) que o currículo deve ser entendido como um elemento vivo, em permanente negociação dos conhecimentos científicos, cotidiano, escolar e midiático, experienciando sentidos, no seu processo de enunciação. $O$ currículo negocia as diferenças, jamais buscando a homogeneização, porque é na heterogeneidade que os sentidos vão se construindo, embasando outros sentidos que descontroem os anteriores. Currículo é produção cultural, um caldeirão de possibilidades antagônicas, ambivalentes, instáveis e dinâmicas em que transitam os conhecimentos. Segundo Corazza (2002), o currículo deve ser produzido utilizando todos os saberes para o estudo das existências locais, regionais, nacionais, transnacionais, intercontinentais. 0 currículo deve questionar os nossos próprios limites: "o que estamos fazendo de nós mesmos, dos outros, de nossos trabalhos, vida, meio ambiente, sociedade, mundo, planeta?" (CORAZZA, 2002, p.111). Trabalha pela verdade e, o mais interessante, deve ser exercido em qualquer lugar:

...locais de trabalho e lazer, campo, cais, ilhas, praças, pátios, associações, ginásios, ruas, assentamentos, parques, viadutos, ATÉ em escolas (grifo nosso). Faz questão de ser experenciado em qualquer lugar, onde Ihe seja dada a oportunidade de produzir e contestar verdades, confrontar narrativas, experiências, construir e desconstruir identidades. Prefere acontecer em todos os espaços em que um ser humano for subjetivado, encontros se realizarem, fluxos de saber se esparramarem, forças de vida se afirmarem, flechas de esperança forem lançadas." (CORAZZA, 2002, p.109)
Acrescentamos o espaço midiático como aquele em que também há confrontação de ideias, narrativas, experiências, desconstruindo constantemente a epistemologia tradicional do conhecimento. E é nesse processo de enunciação de produção de sentidos que os conhecimentos se interpenetram e se hibridizam numa construção inacabada (BHABHA, 2011).

O espaço tecnológico também deve ser entendido como arenas de enunciação. Produção de sentidos constantes que levam os usuários contextos múltiplos que se constroem e desconstroem ao mesmo tempo.

Assim, currículo e tecnologia, como construções inacabadas, nos impelem a refletir sobre a articulação tecno-curricular sob o aspecto da suplementaridade.

\section{A QUESTÃO DO SUPLEMENTO TECNO- CURRICULAR}

O conceito de suplemento nos ajuda a entender que múltiplos fios são tecidos durante a navegação por entre janelas e no contato com outros indivíduos nas redes sociais, nos e-mails, blogs, etc. Fios que não cessam. Múltiplas camadas de sentido que se desdobram em outros sentidos, movendo-se numa dinâmica que irá proporcionar outros processos de significação, articulados no entre meio currículo e tecnologia (DERRIDA, 2005).

(m)as o suplemento supre. Ele não acrescenta senão para substituir. Intervém ou se insinua em-/ugar-de; se ele colma, é como se cumula um vazio. Se ele representa e faz imagem, é pela falta anterior de uma presença. Suplente e vicário, o suplemento é um adjunto, uma instância subalterna que substitui. Enquanto substituto, não se 
acrescenta simplesmente à positividade de uma presença, não produz nenhum relevo, seu lugar é assinalado na estrutura pela marca de um vazio. Em alguma parte, alguma coisa não pode-se preencher de si mesma, não pode efetivar-se a não ser deixando-se colmar por signo e procuração. O signo é sempre o suplemento da coisa própria (DERRIDA, 1999, p. 178).

Derrida (2005) nos permite inferir sobre a articulação tecno-curricular como uma construção/desconstrução crítica que se movimenta na contínua busca por uma plenitude e que, na realidade, está em permanente erosão. 0 suplementar tecnocurricular é rico, instigante, e se desdobra num caldeirão de possibilidades nas relações entre os sujeitos, na produção curricular, nos processos de significação e de identificação, mediatizados pela tecnologia, expurgando binarismos em consequencia de outras linguagens, linguagens múltiplas, midiáticas, que se revelam nas diferenças. Eis uma questão que emana do conceito de suplemento tecno-curricular: a différance. A tecnologia impulsiona esse processo da différance, um constante diferimento que revela uma incompletude no currículo, como assim propõe Derrida (apud HEUSER, 2008), interrogando 0 universo conceitual, pretensamente fixo, em que vivemos e que compõe o currículo de nossas escolas. O mundo tecnológico se irrompe como um universo instável que abala a totalidade, contribuindo para a produção de sentidos constantemente alterados.

A différance é o que faz com que o movimento da significação não seja possível a não ser que cada elemento dito "presente", que aparece sobre a cena da presença, se relacione com outra coisa que não ele mesmo, guardando em si a marca do elemento pas- sado e deixando-se moldar pela marca da sua relação com o elemento futuro, relacionando-se o rastro menos com aquilo que se chama presente do que àquilo a que se chama passado, $\mathrm{e}$ constituindo aquilo que chamamos presente por intermédio dessa relação com o que não é ele próprio: absolutamente não ele próprio, ou seja, nem mesmo um passado ou um futuro como presentes modificados. É necessário que um intervalo o separe que não é ele para que ele seja ele mesmo (DERRIDA, 1991, p. 45).

Assim, o suplemento tecnológico produz constantes diferenças que se articulam no jogo de rastros numa cadeia indecidível (HEUSER, 2008). Caracteriza-se pela adição a uma instância já completa, mas que logra de uma insuficiência. "O suplemento é um excesso, uma plenitude enriquecendo outra plenitude" (DERRIDA, 1999, p. 177). Há acúmulo, acréscimo, justaposição. Desse modo, camadas de leitura provenientes dos vários acessos às informações de sites, por exemplo, vão se sobrepondo, ativando outros movimentos e outras relações. Construir um blog, navegar por entre páginas ou fazer uma análise crítica das mensagens veiculadas nos meios de comunicação são movimentos pelos quais os sentidos, as ideias, as concepções não podem mais ser entendidos com base em uma ordem dicotomizada, pertencente ao sensível ou ao inteligível. Estamos diante de uma Era em que o pensamento interroga a linearidade, abalando o todo, fazendo tremer a totalidade (HEUSER, 2008). Neste processo de diferir, a arena tecno-curricular se torna um espaço de enunciação cultural, pois os sentidos são significados continuamente, sem se repetir. Os sujeitos, ao interagirem com a tecnologia e assim com outros sujeitos tecnológicos e outros 
conhecimentos, criam processos de significação rasurados pela diferença. Esses processos são atos de tradução que se demarcam na enunciação. Um trabalho parceiro entre currículo e tecnologia é emergente e inevitável, pois estamos diante da necessidade da quebra de paradigmas conceituais que ao longo dos anos têm-se tentado consolidar no currículo. Portanto, precisamos pensar no intraduzível, ou seja, currículo e tecnologia constantemente iteram-se, produzindo novos signos tecnocurriculares. Significante e significado se descolam e se movem por entre novos significantes e significados.

E daí incide o duplo, o deslizamento do pensamento, das ideias, entre a presença e a ausência, o real e o virtual. No contato com a gama de informações circulantes nos aparatos tecnológicos, os sujeitos se vêem diante do perturbador e do instável. São terceiros espaços criados continuamente que movimentam o híbrido tecnocurricular (BHABHA, 2011).

\section{O HÍBRIDO TECNOLÓgICO: PARA ALÉM DA FERRAMENTA EM SI}

O conceito de hibridismo que Bhabha (2011) nos apresenta se agrega aos processos de suplementaridade e différance que simultaneamente movimentam e dinamizam os sentidos com, pela e para a tecnologia neste turbilhão contemporâneo. $\mathrm{O}$ entendimento da intensidade das comunicações, sob a perspectiva híbrida, bem como da multiplicidade de linguagens e dos sujeitos que transitam por entre espaços fluidos nos mundos imaginados, como cita Appadurai (2004), permite-nos conjecturar sobre as fendas, os deslizamentos, os escapes de sentidos que vão se deslocando no processo das ambivalências de sentidos e ideias. 0 contato dos alunos com as informações que circulam no meio virtual provoca um movimento de criação de significantes e significados que desloca o signo tecnológico e cria um processo conflituoso, extremamente positivo, que deve ser aproveitado no entrelace com o currículo como veia de discussões. Entendemos a tecnologia como um caldeirão de possibilidades em constante ebulição, formando ondas crescentes, antagônicas e ambivalentes que enunciam 0 diferente, indo além da mera conceituação como ferramenta.

Dussel (2002) menciona que o termo "híbrido" traz um novo território que serve de balizador para entendermos o dinamismo das relações em função dos avanços da comunicação e das tecnologias. Há muitas informações circulando num território mais móvel, menos afincado, que se desestrutura constantemente. E mesmo com o alerta de Dussel (2002) sobre os riscos que o termo híbrido acarreta (por exemplo, o obscurecimento das desigualdades presentes em nossa sociedade), tendemos ao híbrido, correremos o risco com vistas ao entendimento dos processos de suplementaridade e différance que, nas suas ambivalências, promovem a negociação de sentidos e produções outras de significação nos meandros das relações tecnológicas.

Nas últimas décadas, a noção de hibridismo ganhou um impulso diverso daquele proveniente da concepção biológica para descrever os fenômenos difusos, complexos e fragmentados da cultura contemporânea. Como já mencionamos, a complexidade não é patrimônio da contemporaneidade. A novidade de nossos tempos é a ruptura com a ideia de pureza, acentuando-se a mescla e a contaminação dos sentidos e das ideias num processo extremamente produtivo em que os significados se rompem e se associam, ao mesmo tempo, numa simultaneidade impossível do mesmo e do outro. Ambas as 
coisas e uma terceira também (BHABHA, 2013). Dessa maneira, a tecnologia enseja uma prática contra-discursiva, implícita na ambivalência que subverte os signos tecnológicos.

O suplemento tecno-curricular remete ao híbrido tecno-curricular. Percebemos que essa remessa ao emprego do termo "híbrido" acarreta responsabilidades e precisa ser analisada mais detidamente, até para não nos contentarmos em observar o óbvio, como alerta Dussel (2002), e ingenuamente celebrarmos uma nova concepção sem avaliarmos as práticas culturais e políticas em que se dá esse hibridismo. Isso é extremamente importante para pensarmos no trabalho tecno-curricular sob uma perspectiva mais factível, próxima à realidade em que hoje se encontram nossos jovens e adolescentes, nativos digitais. Na medida em que esses espaços de enunciação se interpenetram num movimento de suplementaridade, ou seja, um supre a falta do outro sem nunca alcançarem uma plenitude num jogo contínuo, há também uma mistura que é extremamente positiva. Há uma ruptura e uma associação de sentidos, ao mesmo tempo, que se desvela em múltiplas produções de conhecimento. São produções nos "terceiros espaços da enunciação" (RUTHEFORD, 1990). Não é uma localização física de um espaço, mas é a fluidez no campo das ideias que se movimentam de forma ambivalente e contraditória pela disputa por significação, evidenciando de maneira bastante salutar a diferença cultural. $O$ processo de hibridização subsidiado em Bhabha (2011) ocorre mediante negociações e os discursos vão adquirindo sentidos outros, que não é nem a prevalência de um determinado discurso, nem de outro, mas ambos e, ao mesmo tempo, nenhum. Para o autor, a questão não é o rastreamento de dois momentos originais dos quais emerge um ter- ceiro, mas uma fenda que traz vestígios daqueles sentimentos e práticas que a informam, pondo em conjunto os vestígios de alguns outros sentidos ou discursos. Por conseguinte, ratificamos que a articulação tecno-curricular gera algo diferente, algo novo e irreconhecível, uma nova área de negociação de sentidos e representação. Por meio do híbrido, a navegação cibernética torna-se totalmente incomensurável, contaminando as ideias aparentemente imutáveis, abrindo novas frentes de suplementaridade no rol de conhecimentos ilimitados que são produzidos no currículo.

O espaço da "terceridade" nas redes virtuais abre uma área de "interfecção" (BHABHA, 2013) em que a novidade de práticas culturais transita em "discordância genérica" e "justaposição inesperada". O terceiro espaço suplementar introduz uma necessidade imperiosa de expansão do sistema sensório e do próprio corpo em direção a novas dimensões inimagináveis, talvez impossíveis. E nesse movimento de traduzir o intraduzível, o terceiro espaço é deslocado, evidenciando as relações híbridas dos elementos incomensuráveis que estão continuamente, contingencialmente, retraçando fronteiras, expondo os limites entre o real e virtual. E nessa fronteira movediça, deparamo-nos com algo além, intervalar entre real e virtual, um futuro intersticial que emerge no "entre-meio", no "entre-lugar" (BHABHA, 2013).

\section{CONCLUSÃO}

O "além" não é nem um novo horizonte, nem um abandono do passado...Inícios e fins podem ser os mitos de sustentação dos anos do meio século, mas neste "fin de siècle", encontramo-nos no momento de trânsito em que espaço e tempo se cruzam para produzir figuras 
complexas de diferença e identidade, passado e presente, interior e exterior, inclusão e exclusão. Isso porque há uma sensação de desorientação, um distúrbio de direção, no "além": um movimento exploratório incessante, que o termo francês "au-delà" capta tão bem - aqui e lá, de todos os lados, "fort/da", para lá e para cá, para frente e para trás (BHABHA, 2013, p.19).

Essa citação de Bhabha (2013) revela o sentido do "além" que intitula o texto: a concepção exclusivista da tecnologia como ferramenta educacional inviabiliza um trabalho necessário às prerrogativas do mundo globalizado. É imprescindível considerar que a articulação tecno-curricular faz parte de um movimento de sentidos que está presente na escola, na fluidez dos conhecimentos dos dias atuais. Então, ir além da ferramenta significa algo a mais. Significa criar algo novo, levando em conta que presente, passado e futuro estão em relações fronteiriças, num espaço onde os conhecimentos se hibridizam e, ao se hibridizarem, produzem novos sentidos sem unidade ou fixidez (BHABHA, 2013).

A proposta deste artigo foi trazer à tona questões importantes relativas aos novos processos de constituição de sentidos dos sujeitos que transitam nos espaços virtuais e produzem um emaranhado de conhecimentos que estão em permanente reconfiguração. Sujeitos com diferentes línguas, diferentes saberes em constante processo de diferir nas fronteiras entre o real e o virtual em que ali se hibridizam infinitas culturas. Jacques Derrida e Homi K. Bhabha são expoentes autores que abordam conceitos importantes para pensarmos nesta nova Era, marcada por tecnologias revolucionárias com triunfos da ciência, revolução nos transportes e nas comunicações (HOBSBAWN, 1995). Estamos diante da "estrangeiridade das línguas" que transitam nos espaços escolares que requer novos entendimentos sobre os modos de significação discursivos e culturais, permanentemente em conflito, em constante contestação e fluxo causado pelos sistemas diferenciais de significação social e cultural (BHABHA, 2013). São as dobras e pregas da linguagem tecnológica in actu (enunciação) que expõem o signo da produção de sentidos, quebrando a linearidade entre significante e significado dos conhecimentos.

Portanto, suplementaridade, différance e hibridismo nos ajudam a entender o desalinhamento proveniente do navegar virtual, o deslocamento de todas as lógicas que um dia pensamos estarem estruturadas e que agora se desvelam na tensão dos sentidos, dos sites, do facebook, do twitter, dos blogs no dinâmico aqui e lá, estar ali e acolá. Vidas na fronteira da articulação tecno-curricular. "Uma fronteira não é o ponto onde algo termina, mas como os gregos reconheceram, a fronteira é o ponto a partir do qual algo começa a se fazer presente." (HEIDEGGER apud BHABHA, 2013, p. 19).

\section{REFERÊNCIAS BIBLIOGRÁFICAS:}

APPADURAI, A. Dimensões culturais da globalização: a modernidade sem peias. Lisboa: Teorema, 2004.

\section{BAHKTIN, M. Marxismo e filosofia da} linguagem. São Paulo: Hutec, 2011.

BARRETO, R. G. A apropriação educacional das tecnologias da informação e comunicação. In: LOPES, A. R. \& MACEDO, E. (orgs.) Currículo: Debates Contemporâneos, v.2. São Paulo: Cortez, 2002. 




BHABHA, H. O bazar global e o clube dos cavaleiros ingleses. Rio de Janeiro: Rocco, 2011.

BHABHA, H. O local da cultura. Belo Horizonte: UFMG, 2013.

BRASIL. Ministério da Educação e do Desporto. Chamada pública de tecnologias educacionais. Disponível em: http://www.tecnologiaseducacionais.mec.go v.br. Acesso em: 20 abr. 2014.

CORAZZA, S. M. Diferença pura de um póscurrículo. In: LOPES, A. C. \& MACEDO, E. (orgs.) Currículo: Debates Contemporâneos, v.2. São Paulo: Cortez, 2002.

DERRIDA, J. A farmácia de Platão. São Paulo: Iluminuras, 2005.

Gramatologia. São Paulo: Perspectiva, 1999.

Margens da filosofia. Campinas:

Papirus, 1991.

DUSSEL, I. O currículo híbrido: domesticação ou pluralização das diferenças. In: LOPES, A. R.; MACEDO, E. (orgs.). Currículo: debates contemporâneos. São Paulo: Cortez, 2002, p. 55 - 77.

HOBSBAWN, E. J. Era dos extremos: o breve século XX: 1914-1991. São Paulo: Companhia das Letras, 1995.

LOPES, A. C.; MACEDO, E. Teorias de currículo. Rio de Janeiro: Cortez, 2011.

RUTHEFORD, J. The third space. An interview with Homi Bhabha. In: RUTHERFORD, J. (org.). Identity - community, culture, difference. Londres: Lawrence \& Wishart, 1990 , p. $35-41$.

SCHIMIDT, R. T. Pensamento-compromisso de Homi Bhabha: notas para uma introdução. In: BHABHA, H. 0 bazar global e o clube dos cavalheiros ingleses. Organização: Eduardo F. Coutinho. Rio de Janeiro: Rocco, 2011. 